\title{
Calidad de la leche cruda para consumo humano en dos localidades de Sucre, Colombia
}

\author{
German Arrieta $B^{1} \bowtie(0)$ M.Sc, Luty Gomezcaceres $P^{1} \bowtie(0)$ M. Sc, Dalila Albis $F^{1} \bowtie(0)$ M.Sc,

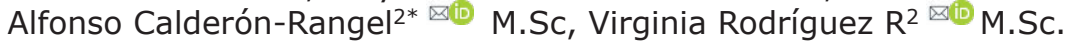

${ }^{1}$ Corporación Universitaria del Caribe (CECAR), Grupo Salud Pública y Auditoría en Salud, Sincelejo, Sucre. ${ }^{2}$ Universidad de Córdoba, Facultad de Medicina Veterinaria y Zootecnia, Instituto de Investigaciones Biológicas del Trópico, Berástegui, Ciénaga de Oro, Córdoba, Colombia.

*Correspondence: acalderonr@correo.unicordoba.edu.co

Recibido: Julio 2018; Aceptado: Febrero 2019; Publicado: Septiembre 2019.

\section{RESUMEN}

Objetivo. Determinar la calidad fisicoquímica, microbiológica y recuento de células somáticas de leches crudas que se distribuyen para consumo humano en diferentes barrios de Sincelejo y Corozal (Sucre). Materiales y métodos. Mediante un estudio descriptivo de corte transversal, se tomaron 97 muestras de leche cruda; se determinaron algunos parámetros fisicoquímicos, microbiológicos y recuento de células somáticas. Los datos obtenidos se analizaron de acuerdo a la normatividad vigente en Colombia. Resultados. La mayoría de los parámetros fisicoquímicos de las muestras de leche cruda evaluadas se encontraron dentro de los parámetros normales de la legislación colombina. El recuento estándar en placa y el recuento de células somáticas se encontraron por encima de lo permitido por la legislación. Se demostró la presencia de coliformes totales, coliformes fecales, antibióticos y adulterantes como sacarosa y almidones. Conclusiones. La leche cruda que se distribuye para consumo humano en Sincelejo y Corozal presenta buena calidad fisicoquímica pero deficiente calidad microbiológica; se hace necesario incrementar la vigilancia y exigir al eslabón primario de la cadena láctea la producción de leche de excelente calidad.

Palabras clave: Alimentos, antibióticos, economía, riesgo, zoonosis (Fuente: NAL USDA).

\section{ABSTRACT}

Objective. To determine the physicochemical, microbiological and somatic cell count of raw milks which are marketed for human consumption in neighborhoods of Sincelejo and Corozal (Sucre). Materials and methods. A cross-sectional study was carried out in 97 samples of raw milk sold for human consumption in different neighborhoods of Sincelejo and Corozal (Sucre). Physical-chemical, microbiological and somatic cell count parameters were determined. The data obtained were analyzed according to the regulations in normative measures in Colombia. Results. Most of the physical-chemical parameters of the raw milk samples analyzed were found within the normal range according to Colombian legislation. The standard plate count and somatic cell count was found to be above what is allowed by the legislation. The presence of total and fecal coliforms, antibiotics and adulterants such as sucrose and starches were determined. Conclusions. Raw milk is distributed for human consumption in Sincelejo and Corozal presents good physical-chemical quality but poor microbiological quality; it becomes necessary to increase surveillance and to demand the production of excellent quality milk in the primary sector in the dairy chain.

Keywords: Antibiotics, foods, risk, trade, zoonoses (Source: NAL USDA).

Como citar (Vancouver)

Arrieta BG, Gomezcaceres PLc, Albis FD, Calderón-Rangel A, Rodríguez RV. Calidad de la leche cruda para consumo humano en dos localidades de Sucre Colombia. Rev MVZ Cordoba. 2019; 24(3):7355-7361. DOI: https://doi.org/10.21897/rmvz.1829

(c)(1) () (C) Attribution 4.0 (https://creativecommons.org/licenses/by-nc-sa/4.0/), que permite a otros distribuir, remezclar, retocar, y crear a partir de su Attribution 4.0 (https://creativecommons.org/licenses/by-nc-sa/4.0/), que permite a otros distribuir, remezclar, retocar, y cre
obra de modo no comercial, siempre y cuando den crédito y licencien sus nuevas creaciones bajo las mismas condiciones. 


\section{INTRODUCCIÓN}

La leche aporta nutrientes esenciales como calcio, magnesio, selenio, riboflavina, cianocobalamina y ácido pantoténico, igualmente es una fuente esencial de energía y proteínas de alta calidad. La leche y sus derivados lácteos hacen que dietas apoyadas sólo en vegetales sea más variada. La leche de origen animal cumple un rol significativo en la dieta de los infantes, especialmente en poblaciones con acceso restringido de otros alimentos de procedencia animal como la carne (1).

Es una preocupación mundial, la producción de alimentos de óptima calidad para el consumo humano y se debe asegurar en los diferentes escenarios la producción de materias primas de óptima calidad; en una leche de excelente calidad, los porcentajes de proteína mayores deben ser $>$ a $3.2 \%$; grasa > a $3.5 \%$; sólidos totales > a $12.2 \%$; recuento de mesófilos < a $50000 \mathrm{Ufc} /$ $\mathrm{mL}$; recuento de células somáticas $<100000 \mathrm{CS} /$ $\mathrm{mL}(2)$; igualmente la normatividad en Colombia dispone que la leche para consumo humano no debe presentar inhibidores o antibióticos, adulterantes y ser inocua (3).

Dentro de los factores que han influido para el consumo de la leche cruda en Colombia son los bajos grados de escolaridad y el menor costo (4), igualmente, la creencia que la leche cruda presenta un alto valor nutricional en comparación con la leche pasteurizada; también el consumo de leche cruda por ser un alimento completo, junto a su estado líquido y su manejo deficiente, es un excelente medio para la proliferación bacteriana y tiene un impacto directo en la trasmisión de enfermedades producidas por alimentos o $\operatorname{ETA}(5,6)$.

En Colombia, durante el 2013, se comercializaron y se expendieron 702.827 litros/día de leche cruda, lo cual representó el $4 \%$ de la producción nacional y su comercio se realizó en el mismo municipio y 5.078 personas devengaron su sustento de este comercio (4). En Sincelejo, existe un gran número de personas que devengan su sustento económico de la comercialización de la leche cruda (7).

El consumo de leche cruda es una costumbre en todo el territorio colombiano y se ha reportado que este comercio se presentó en 623 municipios y en muchas regiones llega a ser un producto diferenciado, con canales propios de comercialización y un consumidor final cautivo (4). El consumo de leche cruda fue reconocido como una de las principales causas de ETA en USA y entre 1993 y 2006; produjo 46 brotes que provocaron 930 enfermedades notificadas y 71 hospitalizaciones en personas menores de 20 años de edad (8). En Colombia no hay evidencias sobre el impacto de las ETA, pero si existen evidencias de la circulación de diferentes patógenos como $B$. abortus, L. monocytogenes, Salmonella spp en leches crudas. $(9,10,11)$.

Por los riesgos en salud pública, el decreto 616 del 2006 prohibió el comercio de la leche cruda para consumo humano (12), pero el decreto 2838 de ese mismo año hizo una modificación de carácter transitoria para la venta, comercialización y enfriado de la leche cruda para consumo humano directo (13). Finalmente el decreto 1880 de 2011, estableció los requisitos mínimos para el consumo humano directo de leche cruda en Colombia. El objetivo general fue conocer la calidad fisicoquímica, microbiológica y el recuento de células somáticas en leches crudas que se distribuyen para consumo humano en diferentes barrios de Sincelejo y Corozal (Sucre).

\section{MATERIALES Y MÉTODOS}

Tipo de estudio. Descriptivo de corte transversal.

Lugar de estudio. La toma de las muestras se implementó en los municipios de Sincelejo ubicado en la subregión Montes de María y Corozal subregión Sabanas; municipios ubicados en el departamento de Sucre, localizado al noroeste de Colombia y dentro de la región del Caribe; donde predomina el bosque seco tropical (BST) donde prevalece la ganadería y la producción de leche es uno de los renglones básicos de la economía $(14,15)$.

Toma de las muestras. Se tomaron 97 muestras de leche cruda que se distribuyen para consumo humano directo en diferentes barrios de Sincelejo y Corozal (Sucre); cada muestra fue homogenizada por medio de un agitador manual de acero inoxidable estéril durante tres o cuatro minutos, posteriormente con un cucharon de acero inoxidable estéril se tomó dos muestras de $200 \mathrm{~mL}$ cada uno en dos recipientes estériles previamente identificados. Todas las muestras, se recolectaron en frascos estériles tapa rosca azul, previamente rotulados que se conservaron en cavas de icopor asegurando una temperatura entre 4 y $7 \mathrm{C}^{\circ}$, hasta el envío a un laboratorio de referencia, dentro de las doce horas siguientes a la toma y se verificaron la temperatura de cavas y muestras para asegurar la cadena de frio.

En la primera muestra, se determinó el porcentaje de grasa (\% de grasa), porcentaje de proteína (\% de proteína), porcentaje de sólidos no grasos (\% de SNG), porcentaje de sólidos totales (\% de ST), recuento estándar en placa o recuento de mesófilos por espectroscopia con infrarrojos y 
recuento de células somáticas (RCS) por citometría de flujo. En la segunda replica en el Laboratorio del Instituto de Investigaciones Biológicas del Trópico (IIBT) de la Universidad de Córdoba, se estableció la densidad (termolactodensímetro), $\mathrm{pH}$ ( $\mathrm{pH}$ metro), acidez (titulación con hidróxido de sodio $0.1 \mathrm{~N}$ ), adulterantes (sacarosa, solución de bilis de buey), neutralizantes (oxalato de potasio), almidones (lugol), solidos no grasos (índice refractométrico refractómetro Bertuzzi), coliformes totales, coliformes fecales por un método comercial y residuos de antibióticos mediante una técnica comercial cualitativa. Las muestras se procesaron en menos de 24 horas después de su recolección.

Análisis de resultados. Los datos obtenidos se tabularon en una hoja de Excel y se implementó estadística descriptiva, usando el software SAS. Los índices obtenidos se compararon con el decreto 616 del 28 de febrero del 2016 y el decreto 1880 del 27 de mayo de 2011, del Ministerio de la Protección Social, que regula los requisitos que debe cumplir la leche cruda para el consumo humano en Colombia.

\section{RESULTADOS}

El $80.41 \%$ (78/97) de las muestras de leche cruda, se recolectaron en Sincelejo y el $19.59 \%$ (19/97) en Corozal (Sucre). En la tabla 1 se presentan los promedios de los parámetros fisicoquímicos, microbiológicos y de células somáticas en leches crudas que se distribuyeron para consumo humano en diferentes barrios de Sincelejo y Corozal. Estos comercializadores informales vendieron 8.434 litros/día, con un promedio de 87 litros/día.

Tabla 1. Parámetros fisicoquímicos, microbiológicos y células somáticas en leches crudas que se comercializan para consumo humano en las calles de Sincelejo y Corozal (Sucre).

\begin{tabular}{lcc}
\hline \multicolumn{1}{c}{ Parámetro } & Resultados & Decreto 616/1880 \\
\hline Densidad (g/mL) & 1.029 & $1.030-1.030$ \\
Acidez (\% de ácido láctico) & 0.17 & $0.13-0.17$ \\
$\mathrm{pH}$ & 6.96 & \\
Grasa (\%) & 4.95 & Mayor a 3.0 \\
Proteína (\%) & 3.45 & Mayor a 2.9 \\
Solidos no grasos (\%) & 8.79 & $8.7-8.4$ \\
Solidos totales (\%m/v) & 13.84 & Mayor a 11.3 \\
Mesófilos (Ufc/mL) & 1461866 & 700000 \\
Células somáticas (CS/mL) & 1002382 & \\
\hline
\end{tabular}

La distribución por rangos del recuento estándar en placa (SPC) o mesófilos, indicador de los procesos de obtención y almacenamiento de la leche, se presenta en la tabla 2 y la distribución del recuento de células somáticas (RCS), indicador de la sanidad de la ubre (mastitis) se muestra en la tabla 3.
Tabla 2. Distribución de los mesófilos en leches crudas que se comercializan para consumo humano en Sincelejo y Corozal (Sucre).

\begin{tabular}{cccc}
\hline Rango (Ufc/mL) & $\mathbf{n}$ & Frecuencia & $\begin{array}{c}\text { Frecuencia } \\
\text { acumulada }\end{array}$ \\
\hline < de 25.000 & 3 & 3.09 & 3.09 \\
25.001 a 50.000 & 0 & 0.00 & 3.09 \\
50.001 a 100.000 & 3 & 3.09 & 6.18 \\
100.001 a 150.000 & 8 & 8.25 & 14.43 \\
150.001 a 200.000 & 7 & 7.22 & 21.65 \\
200.001 a 300.000 & 11 & 11.34 & 32.99 \\
300.001 a 500.000 & 6 & 6.19 & 39.18 \\
500.001 a 700.000 & 1 & 1.03 & 40.21 \\
> 700.001 & 58 & 59.79 & $\mathbf{1 0 0 . 0 0}$ \\
\hline TOTAL & $\mathbf{9 7}$ & $\mathbf{1 0 0 . 0 0}$ & \\
\hline
\end{tabular}

Tabla 3. Distribución de las células somáticas en leches crudas que se comercializan para consumo humano en Sincelejo y Corozal (Sucre).

\begin{tabular}{ccc}
\hline Rango $(\mathbf{C S} / \mathbf{m L})$ & $\mathbf{n}$ & \% \\
\hline$<$ a 100.000 & 0 & 0 \\
100.000 a 200.000 & 5 & 5.15 \\
200.000 a 300.000 & 10 & 10.31 \\
300.000 a 500.000 & 26 & 26.80 \\
500.000 a 700.000 & 11 & 11.34 \\
700.000 a 1.000 .000 & 6 & 15.47 \\
$>1.000 .000$ & 30 & 30.93 \\
\hline TOTAL & $\mathbf{9 7}$ & $\mathbf{1 0 0 . 0 0}$ \\
\hline
\end{tabular}

La determinación de adulterantes como la sacarosa fue del $4.10 \%$, del $1.03 \%$ almidones o féculas y sólo en el 7.21 de las muestras de leche cruda se detectó la presencia de inhibidores o antibióticos.

\section{DISCUSIóN}

Se determinó que el promedio de la densidad de las muestras de leche (Tabla 1), está por debajo del rango establecido en la legislación colombiana; valores por debajo del rango establecido en la normatividad en Colombia, puede estar asociado con varios factores dentro de los cuales se pueden mencionar la adulteración con solutos (16), deficiencias nutricionales de las vacas (17), altos recuentos de mesófilos y células somáticas $(18,19)$.

El $32.96 \%$ de las muestras, la densidad se determinó por fuera de lo establecido en el decreto 616; pero valores normales de la densidad en leche cruda han sido reportados en Sucre $(20,21)$.

La acidez presentó un promedio de $0.17 \%$ de ácido láctico, promedio alto y para disminuir el incremento de la acidez por la falta de refrigeración y las altas temperaturas ambientales, los expendedores 
cuentan con clientes fijos y su distribución se hace en las primeras horas de la mañana con el fin de inhibir la proliferación bacteriana; cuyo objetivo es desdoblar la lactosa en ácido láctico y aumentar la acidez (22). Mayores valores de la acidez han sido determinados en leches en Sucre, donde factores como altas temperaturas ambientales (clima cálido seco), tiempos prolongados de transporte y entrega a la industria han sido implicados como causas determinantes del aumento de la acidez (21). El 54.59\% de las muestras del actual estudio, se encontraron dentro del rango establecido en el decreto 616 para la acidez. El aumento de la acidez es también un indicativo de una inadecuada calidad higiénica y una mala conservación de la leche como materia prima $(2,21,22)$.

El potencial de acidez $\mathrm{opH}$ de una la leche de excelente calidad está entre 6.60 y 6.80 (23); el $\mathrm{pH}$ determinado en este estudio fue del 6.96 con un valor mínimo de 6.30 y un máximo de 10.01 ; sólo el $30.92 \%$ de las muestras se encontraron dentro del rango normal de la legislación colombiana. El aumento en el valor del $\mathrm{pH}$ puede deberse a la falta de refrigeración y de conservación de la leche en garrafones plásticos que favorecen la proliferación bacteriana que degradan la lactosa $(2,21,22)$.

El promedio del porcentaje de grasa fue de $4.95 \%$, valor que está dentro de la norma colombiana. Porcentajes inferiores han sido reportados por diferentes empresas ganaderas de Sucre $(20,21)$. El $6.18 \%$ de las muestras del actual estudio están por debajo de lo establecido en la legislación colombina y puede ser debido a la adulteración con solutos, deficiencias nutricionales de las vacas (17), altos recuento de mesófilos y células somática $(18,19)$.

El promedio del porcentaje de proteína fue de $3.45 \%$; este alto índice de proteína determinado en el actual estudio, puede deberse a los cruces raciales entre Bos taurus y Bos indicus característicos del sistema doble propósito donde hay un menor volumen pero la leche presenta altos porcentajes de proteína, grasa y de sólidos totales entre otros (24). Igualmente, este promedio está por encima de valores reportados en diferentes empresas ganaderas en Sucre $(20,21)$. El $96.91 \%$ de las muestras estuvieron por encima del valor determinado que establece la legislación en la leche líquida cruda para consumo humano procedentes de vacas. En Colombia, en un estudio nacional, se determinó que el $99 \%$ de las muestras de leche cruda estaban por encima del $2.9 \%$ (4).

El promedio del porcentaje de SNG determinado en este estudio fue de $8.79 \%$; valor que califica a estas leches como de excelente calidad (2) y sólo en el $24.74 \%$ de las muestras este valor fue inferior al $8.70 \%$.
El promedio del porcentaje de ST determinado fue de $13.84 \%$; promedio de leches de excelente calidad (3); índices inferiores han sido reportados en Sucre $(20,21)$. Este alto promedio en el actual estudio puede deberse a la presencia de los cruces Bos taurus por Bos indicus que presenta el sistema doble propósito (24). El $4.1 \%$ de las muestras, estaban por debajo del valor determinado en el decreto 616 y en un estudio nacional de muestras de leche cruda para consumo humano determinó que el $44.5 \%$ estaban por debajo de lo establecido en el decreto 616 (4).

El recuento de mesófilos aerobios obtenido en promedio fue de $1461866 \mathrm{Ufc} / \mathrm{mL}$, índice que sobrepasa el nivel permitido por la legislación colombina de $700000 \mathrm{Ufc} / \mathrm{mL}$ (3) y cuando se compara con estándares internacionales es muy alto en leche para consumo humano. Es ideal que los mesófilos sean de $100000 \mathrm{Ufc} / \mathrm{mL}$ o menos $(2,25)$. En Sucre, se han reportado valores muy altos en leche cruda $(20,21)$ que pueden deberse a la falta de higiene en los procesos del ordeño y malas prácticas de conservación y almacenamiento de la leche $(2,26)$.

Solamente el $3.09 \%$ de las muestras presentaron recuentos menores de $50000 \mathrm{Ufc} / \mathrm{mL}$ (Tabla 2), que califica a estas leches como de excelente calidad microbiológica e igual proporción para recuentos de $100000 \mathrm{Ufc} / \mathrm{mL}$ (tabla 2) que clasifica como leches de regular calidad. El $93.82 \%$ de los recuentos de mesófilos fueron altos. La presencia de altos recuentos de mesófilos puede deberse al transporte y venta inadecuada de la leche, carencia de una red de frío, altas temperaturas ambientales, tiempos prolongados de venta y el acopio en materiales no adecuados $(2,26)$.

En Colombia, la normatividad colombiana, no establece el recuento de coliformes totales y coliformes fecales como criterio para evaluar la calidad microbiológica de la leche cruda. La alta carga de bacterias contaminantes en la leche disminuye la vida útil de los productos elaborados y la inocuidad (27). En leche cruda no se puede encontrar más de 1000 coliformes/mL (2). El recuento de coliformes totales y fecales obtenido fue de 838941 coliformes/mL y 182155 coliformes/ $\mathrm{mL}$ respectivamente. La presencia de coliformes fecales es un indicador de contaminación directa de un alimento con materia fecal y supone un riesgo indirecto de adición de otros patógenos $(27,28)$ o la falta de implementación de buenas prácticas durante el ordeño (26). En el Oriente antioqueño, se sugirió que el mejoramiento de las variables del manejo del ordeño incrementa la calidad bacteriológica de la leche (29). 
Este estudio determinó un alto RCS, lo que indica que las leches provienen de vacas con alta la prevalencia de mastitis. El promedio del RCS fue de $1002382 \mathrm{CS} / \mathrm{mL}$ (Tabla 1); lo que evidencia ausencia de programas de prevención y control de la mastitis bovina en esas fincas (30). Un estudio en leches crudas en Galeras, Sucre, indicó que el índice de mastitis fue mayor al $20 \%$ (20). Leches provenientes de cuartos libres de mastitis el RCS es bajo y su incremento es directamente proporcional al aumento de los grados de mastitis $(18,31)$.

El resultado obtenido para la presencia de antibióticos en las muestras de leche fue del $7.21 \%$. La presencia de antibióticos o inhibidores en leche cruda, es un indicador de malas prácticas en el manejo de los medicamentos veterinarios (32) y es un factor de alteración de la salud pública debido a que puede provocar efectos adversos en los humanos como: alergia, choques anafilácticos, disbacteriosis, resistencia antibacteriana, alteración de la microflora intestinal, reducción de la síntesis de proteínas entre otros (33). Un estudio realizado en seis departamentos de Colombia con muestras de leche cruda para consumo humano, determinó que el $5.5 \%$ de las muestras fueron positivas para antibióticos (4). Otra explicación de la presencia de antibióticos o inhibidores en la leche es la comercialización en canales informales donde no se exigen mayores controles (34).
La presencia de adulterantes como sacarosa y otros tiene como objetivo enmascarar la adición de agua a la leche con el fin de restituir sus propiedades fisicoquímicas. En Colombia, se determinó que el $0.5 \%$ de las muestras fueron positivas para almidones (4). La normatividad colombiana establece que la leche para consumo humano y sus derivados lácteos no deben tener ningún tipo de adulterantes (3).

La calidad fisicoquímica de las leches crudas que se distribuyen para consumo humano en diferentes barrios de Sincelejo y Corozal (Sucre) son aptas para consumo humano pero no desde el punto de vista microbiológico y del RCS, donde se presentan graves diferencias que hacen que estas leches no sean adecuadas para consumo humano. Se hace necesario exigir a las empresas ganaderas mejorar todos los parámetros de calidad para producir leches de excelente calidad y a los expendedores asegurar las condiciones de un excelente manejo de post-cosecha para asegurar la inocuidad.

\section{Conflicto de intereses.}

Los autores del presente estudio declaramos que no existe conflicto de intereses con la publicación de este manuscrito.

\section{REFERENCES}

1. Pereira PC. Milk nutritional composition and its role in human health. Nutrition 2014; 30(6):619-627. https://doi.org/10.1016/j. nut.2013.10.011

2. Calderón A, García F, Martínez G. 2006. Indicadores de calidad de leche cruda en Colombia. Rev MVZ Córdoba 2006; 11(1):725-737. https://doi.org/10.21897/ rmvz.457

3. Ministerio de la Protección Social. Decreto 1880. Por el cual se señalan los requisitos para la comercialización de leche para consumo humano directo en el territorio nacional. 2011. [Consultado abril de 2017]. URL Disponible en: https://www.invima. gov.co/normatividad/decretos/Documentos/ Decretos/Alimentos/detail.html.
4. Minsitertio de Salud y Protección Social. Perfil sanitario nacional de leche cruda para consumo humano directo. 2014. [Consultado abril de 2017].URL Disponible en: https://www.minsalud.gov.co/sites/ rid/Lists/BibliotecaDigital/RIDE/VS/PP/SNA/ Perfil-sanitario-nacional-leche-cruda.pdf

5. Headrick ML, Timbo B, Klontz KC, Werner SB. Profile of raw milk consumers in California. Public Health Rep 1997; 112(5):418-422. https://www.ncbi.nlm.nih.gov/pmc/articles/ PMC1381950/

6. Hegarty $\mathrm{H}, \mathrm{O}$ 'Sullivan MB, Buckley J, FoleyNolan C. Continued raw milk consumption on farms: why? Commun Dis Public Health 2002; 5(2):151-156. https://www.ncbi.nlm. nih.gov/pubmed/12166304 
7. Olivero R, Aguas Y, Cury K. Comercialización de leche cruda en Sincelejo, Sucre-Colombia. Rev Colombiana Cienc Anim 2011; 3(1):156163. https://doi.org/10.24188/recia. v3.n1.2011.353

8. David SD. Raw milk in court: Implications for public health policy and practice. Public Health Reports 2012; 127(6):598-601. https://doi. org/10.1177/003335491212700610

9. Mosquera CX, Bernal VC, Muskus LC, Berdugo GJ. Detección de Brucella abortus por PCR en muestras de sangre y leche de vacunos. Rev MVZ Cordoba 2008; 13(3):1504-1513. https://doi.org/10.21897/rmvz.382

10. Motta GJL, Clavijo HJA, Waltero GI, Abeledo MA. Prevalencia de anticuerpos a Brucella abortus, Leptospira sp. y Neospora caninum en hatos bovinos y bubalinos en el Departamento de Caquetá, Colombia. Rev Salud Anim 2014; 36(2):80-89. http://revistas.censa.edu.cu/ index.php/RSA/article/view/440

11. Cogollo-Cordero Y, Rodríguez-Rodríguez V, Calderón-Rangel A. Evidencias moleculares de patógenos asociados a leches crudas en empresas ganaderas doble propósito en Córdoba, Colombia. Agronomía Colombiana 2016; (S1):S1434-1436. http:// www.cienciasagrarias.bogota.unal.edu. co/sites/default/files/IMGS/IICTA2016/ Revista\%20Agronomia\%20Colombiana\%20 $\% 28$ suplemento $\% 29 \% 20$ Congreso $\% 20$ IICTA \%202016\%20Indice.pdf

12. Ministerio de la Protección Social. Decreto 616. Por el cual se expide el Reglamento Técnico sobre los requisitos que debe cumplir la leche para el consumo humano que se obtenga, procese, envase, transporte, comercializa, expenda, importe o exporte en el país. 2006. [Consultado abril del 2017]. URL Disponible en: https://www.ica.gov.co/ getattachment/15425e0f-81fb-4111-b21563e61e9e9130/2006D616.aspx.

13. Ministerio de la Protección Social. Decreto 2838. del 24 de agosto del 2006. Por el cual se modifica parcialmente el Decreto 616 de 2006 y se dictan otras disposiciones. 2006. [Consultado abril del 2017]. URL Disponible en: https://www.ica.gov.co/ getattachment/d3de0922-5311-4ee3-b18633c1f4c5afe7/2006D2838.aspx

14. Aguilera DMM. La economía del departamento de Sucre: Ganadería y sector público. Serie: Documentos de trabajo sobre economía regional. Banco de la Republica: Cartagena. Colombia; 2005. http://www.banrep.gov. co/es/economia-del-departamento-sucreganaderia-y-sector-publico
15. Lombana CJ, Martínez D, Valverde MM, Oquendo JR, Castrillón CJ, Marino W. Caracterización del sector ganadero del Caribe colombiano. Editorial Universidad del Norte: Barranquilla, Colombia; 2012. http://manglar.uninorte. edu.co/handle/10584/1183\#page $=1$

16. Gondim CS, Junqueira RG, Souza SVC, Ruisánchez I, Callao MP. Detection of several common adulterants in raw milk by MIDinfrared spectroscopy and one-class and multi-class multivariate strategies. Food Chem 2017; 230:68-75. https://doi.org/10.1016/j. foodchem.2017.03.022

17. Mach N, Zom RLG, Widjaja HCA, Van Wikselaar PG, Weurding RE, Goselink RMA, et al. Dietary effects of linseed on fatty acid composition of milk and on liver, adipose and mammary gland metabolism of periparturient, dairy cows. J Anim Physiol Anim Nutr 2013; 97:89-104. https://doi.org/10.1111/jpn.12042

18. Calderón $A$, Arteaga $M R$, Rodríguez V, Arrieta GJ, Bermúdez DC, Villareal, VP. Efecto de la mastitis subclínica sobre el rendimiento en la fabricación del queso costeño. Biosalud 2011; 10(2):16-27. http://vip.ucaldas.edu.co/ biosalud/downloads/Revista Biosalud 10(2) COMPLETA.pdf

19. Román S, Guerrero L, Pacheco L. Evaluación de la calidad fisicoquímica, higiénica y sanitaria de la leche cruda almacenada en frío. Revista Cientifica FCV-Luz 2003; 8(2):146152. https://produccioncientificaluz.org/ index.php/cientifica/article/view/14972

20. Botero $A L$, Vertel MM, Flores ML, Medina PJ. Calidad composicional e higiénico-sanitaria de leche cruda entregada en época seca por productores de Galeras, Sucre. Vitae 2012; 19(1):S314-S316. https://aprendeenlinea. udea.edu.co/revistas/index.php/vitae/article/ view/12016/10904

21. Martínez MMM, Gómez SCA. Calidad composicional e higiénica de la leche cruda recibida en industrias lácteas de Sucre, Colombia. Biotec Sec Agrop y Agroind 2013; 11(2):93-100. https://revistas.unicauca. edu.co/index.php/biotecnologia/article/ view/309/0

22. Chacón VA. Comparación de la titulación de la acidez de leche caprina y bovina con hidróxido de sodio y sal común saturada. Agron Mesoam 2006; 17(1):55-61. https:// doi.org/10.15517/am.v17i1.5066 
23. Cámara nacional de industriales de la leche. El libro blanco de la leche y los productos lácteos. 1ra edición, Litho Offset Imprenta: Mexico; 2011. http://infolactea.com/wpcontent/uploads/2016/05/Libro Blanco mail. pdf

24. Rodríguez GYY, Martínez GE. Efecto de la edad al primer parto, grupo racial y algunos factores ambientales sobre la producción de leche y el primer intervalo entre partos en vacas doble propósito. Rev Fac Cs Vets UCV 2010; 51(2):79-91. http://saber.ucv.ve/ojs/ index.php/revisfcv/article/view/71

25. Cervantes F, Cesín A, Mamani I. La calidad estándar de la leche en el estado Hidalgo, México. Rev Mex Cien Pecu 2013; 4(1);7586. https://cienciaspecuarias.inifap.gob.mx/ index.php/Pecuarias/article/view/2827

26. Morales MSA, Rodríguez N, Vásquez JF, Olivera ÁM. Influencia de la práctica de ordeño sobre el recuento de células somáticas (RCS) y unidades formadoras de colonias (UFC) en leche bufalina. Rev UDCA Act \& Div Cient. 2014; 17(1):189-196. https:// revistas.udca.edu.co/index.php/ruadc/ article/view/954/1179

27. Signorini ML Sequeira GJ, Bonazza JC, Dalla SR, Martí LE, Frizzo LS, et al. Utilización de microorganismos marcadores para la evaluación de las condiciones higiénicosanitarias en la producción primaria de leche. Rev Cient FCV-LUZ. 2008; 18(2):207-217. https://produccioncientificaluz.org/index. php/cientifica/article/view/15359

28. Miccio L, Rumi MV, Llorente $P$, Bentancor AB. Contaminación de carne molida con cepas de Escherichia coli shigatoxigénico (STEC) provenientes de comercios minoristas de San Martín, Buenos Aires, categorizados según nivel socioeconómico. InVet. $2011 ; 13(1)$ :3744. https://www. veterinariargentina. com/revista/2012/03/contaminacion-decarne-molida-con-cepas-de-escherichiacoli-shigatoxigenico-stec-provenientesde-comercios-minoristas-de-san-martinbuenos-aires-categorizados-segun-nivelsocioeconomico/
29. Ruiz-Cortés T, Orozco S, Rodríguez LS, Idárraga J, Olivera M. Factores que afectan el recuento de UFC en la leche en tanque en hatos lecheros del norte de AntioquiaColombia. Rev UDCA Act \& Div Cient. 2012; 15(1):147-155. https://revistas.udca.edu.co/ index.php/ruadc/article/view/812/909

30. Cerón-Muñoz MF, Agudelo EJ, MaldonadoEstrada JG. Relación entre el recuento de células somáticas individual o en tanque de leche y la prueba CMT en dos fincas lecheras del departamento de Antioquia (Colombia). Rev Colomb Cienc Pecu. 2007; 20:472-483. http://aprendeenlinea.udea. edu.co/revistas/index.php/rccp/article/ view/324204/20781376

31. Sharma N, Singh NK, Bhadwal MS. Relationship of somatic cell count and mastitis: an overview. Asian-Aust J Anim Sci. 2011; 24(3):429-438. https://doi.org/10.5713/ ajas. 2011.10233

32. Instituto Colombiano Agropecuario. Buenas prácticas en el uso de los medicamentos veterinarios y la inocuidad de los alimentos. Promedios, Bogotá, 2007. https://www.ica. gov.co/getattachment/cf8d4834-dd11-40f2944e-b1ae436ef513/Publicacion3.aspx

33. Máttar S, Calderón A, Sotelo D, Sierra $M$, Tordecilla G. Detección de antibióticos en leches: Un Problema de salud pública. Rev Salud Pública. 2009; 11(4):579590. https://doi.org/10.1590/S0124$\underline{00642009000400009}$

34. Calderón RA, Jiménez PG, García CF. Determinación de buenas prácticas de ordeño en un grupo de gestión empresarial de ganaderos del Altiplano Cundiboyacense. Rev UDCA Act \& Div Cient- 2008; 11(1): 143152. https://revistas.udca.edu.co/index.php/ ruadc/article/view/611/573 